\title{
Mystery Case: Migraine, hearing loss, and blurred vision in a young woman
}

Sanskriti Sasikumar, MD, Jonathan A. Micieli, MD, and Jiwon Oh, MD, PhD

Neurology ${ }^{\circledR}$ 2020;95:e2945-e2950. doi:10.1212/WNL.0000000000011034
Correspondence

Dr. Sasikumar

Sanskriti.sasikumar@

mail.utoronto.ca

\section{Section 1}

A 39-year-old previously healthy woman presented with a 3-week history of progressive frontal headaches that were of pulsatile quality, moderate severity, and associated with occasional photophobia and nausea. She denied a history of headaches and managed her pain without medication. She reported generalized malaise and perioral and bilateral hand paresthesia. At the time of assessment, she also endorsed diminished hearing and tinnitus in her left ear and intermittent blurry vision in both eyes.

On physical examination, the patient was apathetic and in no apparent distress. She denied subjective cognitive deficits, but her Montreal Cognitive Assessment (MoCA) 7.1 score was 26/ 30 (producing only 8 F-words on verbal fluency, impaired abstraction, and missing a word on delayed recall). On cranial nerve inspection, her visual acuity was $20 / 20$ in both eyes and confrontation visual fields were full. Pupils were of equal sizes, with no relative afferent pupillary defect on either side. Dilated fundus examination revealed 1 cotton-wool spot in the right eye and 2 cotton-wool spots in the left eye, with sheathing of a nasal retinal arteriole in the right eye (figure, A). Extraocular eye movements were full, with normal saccades and smooth pursuit. There was no appreciable auditory loss on bedside testing, and the remainder of the cranial nerves were intact. Motor examination revealed normal muscle bulk and tone, power $5 / 5$, and reflexes $2+$ with normal plantar responses. Sensory examination was intact to pinprick and vibration. Cerebellar examination revealed no dysmetria and normal rapid alternating movements. Gait was intact.

\section{Questions for consideration:}

1. What further investigations might assist in making the diagnosis?

2. What features would you expect to see on brain MRI?

3. What are the differential diagnoses to consider? 
Figure Dilated retinal examination, wide-field IV fluorescein angiography, and MRI brain and cervical spinal cord

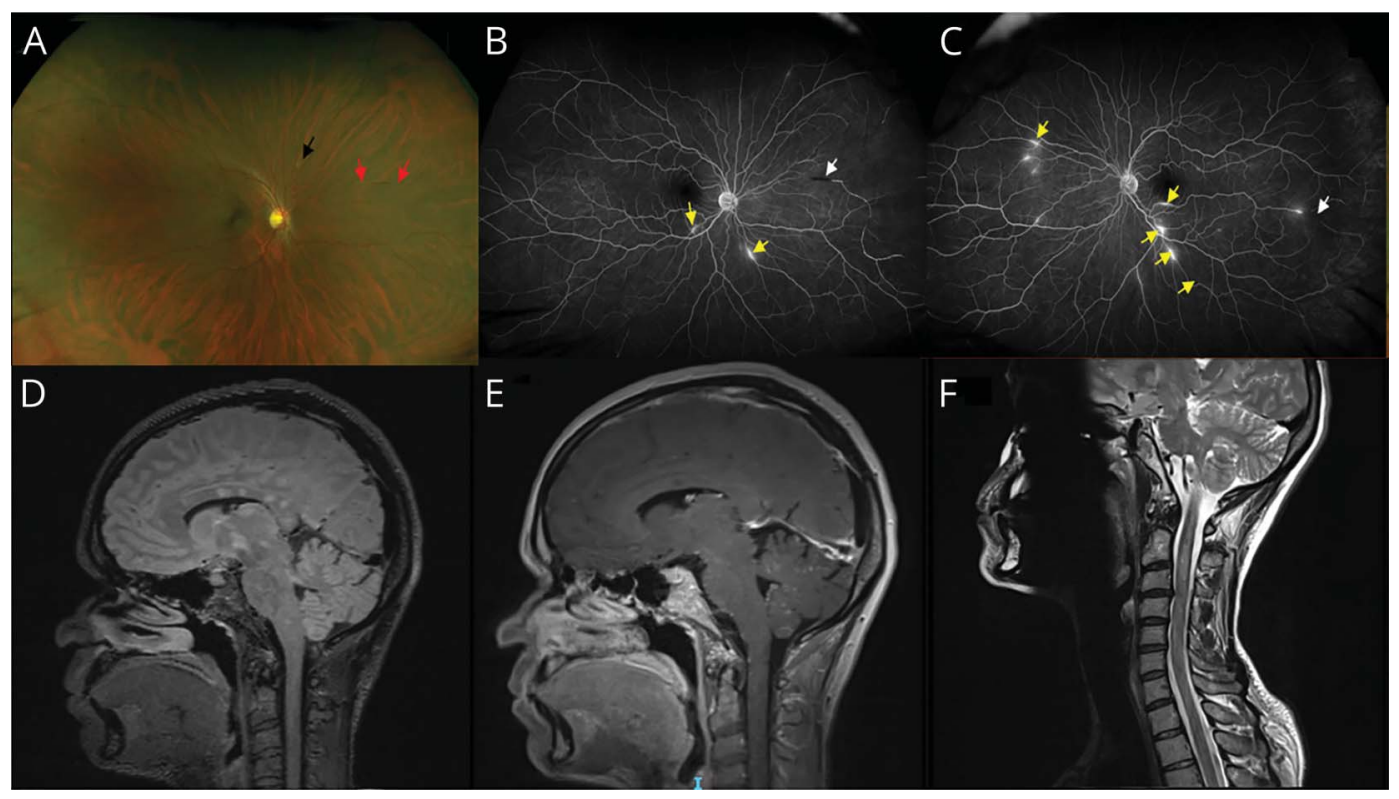

(A) Dilated retinal examination demonstrates a cotton-wool spot (black arrow) and retinal arteriolar sheathing (red arrows). (B, C) Wide-field IV fluorescein angiography demonstrates arteriolar wall hyperfluorescence in areas of normal-appearing retinal vessels (yellow arrows) and areas of retinal arteriolar nonperfusion (white arrows). (D) MRI brain: sagittal fluid-attenuated inversion recovery sequence demonstrates multiple T2 hyperintense lesions in the corpus callosum (snowball lesions), thalamus, and midbrain. (E) MRI brain: sagittal T1-weighted sequence with gadolinium contrast demonstrates multiple foci of enhancement throughout the cerebellum, leptomeninges of the cerebellar folia, brainstem, basal ganglia, and cervical spinal cord. (F) MRI cervical spinal cord: sagittal T2-weighted sequence shows faint areas of hyperintensity at the level of C1-3.

GO TO SECTION 2 


\section{Section 2}

This vignette describes a young woman with subacute encephalopathy characterized by headache and mild cognitive impairment. The retinal findings on fundoscopy prompted further investigation with an IV fluorescein angiogram (IVFA). This revealed arteriolar wall hyperfluorescence in otherwise normal-appearing retinal arterioles, and an area of arteriolar nonperfusion in the right eye (figure, B and C). An audiogram revealed low-frequency sensorineural hearing loss in the left ear.

Routine bloodwork was normal, including complete blood count, liver function tests, and creatinine. Lumbar puncture revealed elevated protein $2.64 \mathrm{~g} / \mathrm{L}$, white cell count of $32 \times 10^{6} /$ $\mathrm{L}$ with a lymphocytic predominance (92\%), and glucose 3.2 $\mathrm{mmol} / \mathrm{L}$ (serum glucose $8 \mathrm{mmol} / \mathrm{L}$ ). CSF cytology, flow cytometry, and infectious workup were negative (bacterial culture, mycobacteria culture, and human herpesvirus screen). There was no intrathecal synthesis of oligoclonal bands. Serum and CSF anti-aquaporin-4 and anti-myelin oligodendrocyte glycoprotein antibodies were negative. Infectious workup for HIV and hepatitis B and C was negative. Serum protein electrophoresis and autoimmune screen (which included antinuclear antibody, rheumatoid factor, anticardiolipin, and $\beta 2$ glycoprotein) were also negative. A malignancy screen performed with a $\mathrm{CT}$ abdomen, chest, and pelvis revealed no abnormalities.

An MRI of the brain and upper cervical cord was obtained because perioral paresthesia can be symptomatic of lesions in the spinal trigeminal nucleus. This showed multiple wellcircumscribed lesions with a predilection for midline structures including the corpus callosum, periventricular white matter, midbrain, thalamus, and pons (figure, D). Some of these lesions demonstrated restricted diffusion. There was fulminant parenchymal and leptomeningeal enhancement (figure, E). Interestingly, the imaging also captured an extensive lesion in the upper cervical spinal cord ( $\mathrm{C} 1-\mathrm{C} 3)$, with cord edema and mild leptomeningeal enhancement (figure, $\mathrm{F}$ ).

GO TO SECTION 3 


\section{Section 3}

The presentation of encephalopathy, ${ }^{1}$ left ear sensorineural hearing loss, and visual distortion from retinal ischemia was suggestive of Susac syndrome. The patient's MRI described the classic finding of snowball T2-hyperintense lesions involving the central fibers of the corpus callosum. ${ }^{2}$ Other suggestive imaging features were leptomeningeal enhancement and periventricular, deep gray matter, cerebellar, and brainstem involvement. ${ }^{1,2}$ Myelopathy is an extremely rare finding in Susac syndrome, and has been described in only 2 prior case reports. ${ }^{3}$ It was therefore imperative to rule out conditions that could mimic this presentation.

Differential diagnoses include inflammatory demyelination (multiple sclerosis or acute disseminated encephalomyelitis), other inflammatory disorders (sarcoid, Behçet disease, chronic lymphocytic inflammation with pontine perivascular enhancement responsive to steroids), lymphoma, and multiple infarcts from vasculitis.

GO TO SECTION 4 


\section{Section 4}

The patient was treated acutely with a 5-day course of $1 \mathrm{~g}$ IV solumedrol and IV immunoglobulin (IVIg) $(2 \mathrm{~g} / \mathrm{kg}$ over 2 days). These were administered simultaneously. She was then transitioned to prednisone $(1 \mathrm{mg} / \mathrm{kg})$ for 1 month, with a plan to slowly taper the dose over several months. She was also started on mycophenolate mofetil (titrated to $1 \mathrm{~g}$ twice daily) and received maintenance IVIg $(1 \mathrm{~g} / \mathrm{kg})$ treatments every 5-6 weeks.

Within days of initiating solumedrol and IVIg, the frequency and severity of headache improved. At the time of discharge, MoCA 7.1 improved to 28/30, with persistent deficits in F-fluency and abstraction. In the following months, the patient's paresthesia and visual distortions became infrequent, but hearing loss persisted. Repeat MRI of the brain and cervical spine 2 months after discharge revealed significant reduction in abnormal signal intensities, resolution of the fulminant enhancement, and no new lesions. Ophthalmologic follow-up also showed a reduced burden of disease.

\section{Discussion}

Susac syndrome is classically described as a triad of encephalopathy, ${ }^{1}$ branch retinal artery occlusions, and sensorineural hearing loss. It can manifest initially with a migrainous headache, and progress to encephalopathy and focal neurologic deficits depending on the intracranial distribution of lesions. ${ }^{4}$ Visual field deficits can be asymptomatic if they occur in the peripheral field, hearing loss is often subtle because lower frequencies are affected first, and encephalopathy can overshadow associated symptoms at initial presentation. ${ }^{4}$ These forme fruste variants refer to subtle neurologic presentations of the disease and can delay diagnosis. ${ }^{4}$ The diagnosis in this vignette was established based on the presence of central callosal lesions on MRI and arteriolar wall hyperfluorescence on IVFA in an area remote from a retinal artery occlusion. $^{5}$

Our understanding of Susac syndrome is constantly evolving. Accumulating evidence suggests that the clinical presentation can extend beyond the classical triad, as there have been 2 described cases of myelopathy. These include an asymptomatic cervical cord lesion in a 25 -year-old woman with an otherwise typical triad, ${ }^{3}$ and an incomplete T4 sensory level in a 23-year-old woman with no appreciable MRI signal change. ${ }^{6}$ Cauda equina syndrome has also been reported. ${ }^{7}$ Therefore, ordering an MRI of the spinal cord may be helpful to establish the extent of disease involvement.

Susac syndrome affects women more than men $(3: 1)$. The peak onset of disease occurs in the third and fourth decades. ${ }^{4}$ Over 300 cases have been reported in the literature, but its true prevalence remains unknown. The disease course varies from being monophasic with spontaneous remission within
1-2 years, polycyclic with frequent remissions, or it can persist and progress for several years without relief. ${ }^{4}$ Encephalopathic patients tend to experience a monophasic illness, whereas those who present with early visual or hearing impairment are likely to experience disease relapse. ${ }^{6}$

Susac syndrome is presumed to be an immune-mediated microangiopathy, which is associated with the production of anti-endothelial cell antibodies. ${ }^{8,9}$ These antibodies are not disease-specific and might be an epiphenomenon, as they are present in multiple other conditions including Kawasaki disease, rheumatoid arthritis, and multiple sclerosis. ${ }^{9}$ The subsequent inflammatory process results in microinfarctions in the brain, retina, and cochlea because of lymphocytic infiltration and destruction of the small and medium-sized vessels. ${ }^{8,9}$

CSF studies in Susac syndrome reveal elevated protein in $84 \%$ of patients (mean $1.6 \mathrm{~g} / \mathrm{L}$ ) and a concurrent mild lymphocytic pleocytosis in $45 \%$ of patients (mean white blood cells $\left.12 \times 10^{9} / \mathrm{L}\right){ }^{6}$ Intrathecal oligoclonal bands are seen in only $4 \%$ of the Susac population. ${ }^{6}$ Compared to demyelinating disorders, the T2-hyperintense lesions in Susac syndrome are smaller and more circular, with a predilection for the corpus callosum. ${ }^{2}$

There is no consensus on the optimal treatment of Susac syndrome. Low-dose aspirin is used to inhibit thrombosis and long-term immunosuppression is generally recommended. ${ }^{10}$ Whereas the duration of treatment varies between individuals, aggressive intervention early in the disease is generally recommended. This results in fewer complications, as the microvasculature in the retina and cochlea are easily damaged and often irreversible. ${ }^{10}$ Corticosteroids and IVIg are preferred during an acute relapse, and long-term immunosuppression is achieved with either mycophenolate mofetil or azathioprine. ${ }^{10}$ Breakthrough or refractory disease can be treated with rituximab or infliximab. ${ }^{10}$

This case demonstrates an early presentation of Susac syndrome, and emphasizes the utility of radiologic findings in guiding investigations when symptoms are subtle. The classic snowball lesions in the corpus callosum directed us to investigate the patient's auditory and visual symptoms and therefore establish the diagnosis. The enhancing lesion observed in her cervical spinal cord is a rarely described feature of Susac syndrome, and demonstrates the heterogeneity of this condition.

\section{References}

1. Dörr J, Radbruch H, Bock M, et al. Encephalopathy, visual disturbance and hearing loss: recognizing the symptoms of Susac syndrome. Nat Rev Neurol 2009;5:683.

2. Susac JO, Murtagh FR, Egan RA, et al. MRI findings in Susac's syndrome. Neurology 2003;61:1783-1787.

3. Hua LH, Donlon SL, Okuda DT. A case of Susac syndrome with cervical spinal cord involvement on MRI. J Neurol Sci 2014;337:228-231.

4. Kleffner I, Duning T, Lohmann H, et al. A brief review of Susac syndrome. J Neurol Sci 2012;322:35-40.

5. Egan RA. Diagnostic criteria and treatment algorithm for Susac syndrome. J Neuroophthalmol 2019;39:60-67. 
6. Dörr J, Krautwald S, Wildemann B, et al. Characteristics of Susac syndrome: a review of all reported cases. Nat Rev Neurol 2013;9:307.

7. Allmendinger AM, Mallery RM, Magro CM, et al. Cauda equina involvement in Susac's syndrome. J Neurol Sci 2014;337:91-96.

8. Jarius S, Kleffner I, Dörr JM, et al. Clinical, paraclinical and serological findings in Susac syndrome: an international multicenter study. J Neuroinflamm 2014;11:46.

9. Magro CM, Poe JC, Lubow M, Susac JO. Susac syndrome: an organ-specific autoimmune endotheliopathy syndrome associated with anti-endothelial cell antibodies. Am J Clin Pathol 2011;136:903-912.

10. Rennebohm RM, Asdaghi N, Srivastava S, Gertner E. Guidelines for treatment of Susac syndrome: an update. Int J Stroke 2018;15:484-494.

\section{Mystery Case Responses}

The Mystery Case series was initiated by the Neurology ${ }^{\circledR}$ Resident \& Fellow Section to develop the clinical reasoning skills of trainees. Residency programs, medical student preceptors, and individuals were invited to use this Mystery Case as an educational tool. Responses to multiple-choice questions formulated using this case were solicited through a group e-mail sent to the American Academy of Neurology Consortium of Neurology Residents and Fellows and through social media. We received 317 responses. The majority of respondents (72\%) had just been in practice for 1-4 years; $56 \%$ were residents or fellows while $35 \%$ were faculty/board-certified physicians; the remainder were medical students or advanced practice providers. Sixty-five percent resided outside the United States. A wide range of practice settings was represented.

A brief vignette of a 39-year-old woman with new-onset frontal headaches, cognitive impairment, perioral and hand paresthesias, diminished hearing and tinnitus, and intermittent blurry vision was presented. When her funduscopic examination pictures were shown, $57.7 \%$ of participants correctly identified retinal arteriolar wall hyperfluorescence, $52.7 \%$ identified retinal arteriolar nonperfusion, and 39.7\% identified retinal arteriolar sheathing. The most common incorrect answer was flame retinal hemorrhages (35.0\%).

Additional results including an audiogram showing lowfrequency hearing loss, CSF analysis showing pleocytosis and high protein, and brain and cervical spinal cord MRI were presented. Most participants (78.5\%) correctly responded that Susac syndrome was the most likely diagnosis. The most common incorrect responses were neuromyelitis optica spectrum disorder $(6.0 \%)$, primary angiitis of the CNS (5.4\%), and multiple sclerosis (4.4\%). Among other findings, the MRI showed snowball lesions in the corpus callosum. These are very suggestive of Susac syndrome. Published diagnostic criteria for Susac syndrome consist of clinical and auxiliary test findings of brain, retinal, ${ }^{1}$ and vestibulocochlear involvement. This patient fulfills the criteria for definite Susac syndrome.

Finally, the participants were asked which was the best treatment. Acute therapy with high-dose steroids or IVIg followed by the initiation of mycophenolate mofetil was correctly chosen by $64.7 \%$. The most common incorrect answers were starting eculizumab (12.3\%) or fingolimod (8.2\%) after acute therapy. These options would be indicated in neuromyelitis optica spectrum disorder or multiple sclerosis, respectively. Cyclophosphamide was incorrectly chosen by $7.3 \%$ of participants. Although this drug can be used in cases refractory to high-dose steroids or IVIg, it would not be the first choice. ${ }^{2}$

\section{Alonso Zea Vera, MD}

Cincinnati Children's Hospital Medical Center

\section{Study funding}

No targeted funding reported.

\section{Disclosure}

The authors report no disclosures relevant to the manuscript. Go to Neurology.org/N for full disclosures.

\section{Appendix Authors}

\begin{tabular}{lll}
\hline Name & Location & Contribution \\
\hline $\begin{array}{l}\text { Sanskriti } \\
\begin{array}{l}\text { Sasikumar, } \\
\text { MD }\end{array}\end{array}$ & $\begin{array}{l}\text { University of } \\
\text { Toronto, Canada }\end{array}$ & $\begin{array}{l}\text { Execution and write-up of first } \\
\text { draft of the manuscript }\end{array}$ \\
\hline $\begin{array}{l}\text { Jonathan A. } \\
\text { Micieli, MD }\end{array}$ & $\begin{array}{l}\text { University of } \\
\text { Toronto, Canada }\end{array}$ & Reviewing the manuscript \\
\hline $\begin{array}{l}\text { Jiwon Oh, MD, } \\
\text { PhD }\end{array}$ & $\begin{array}{l}\text { University of } \\
\text { Toronto, Canada }\end{array}$ & $\begin{array}{l}\text { Conception and reviewing the } \\
\text { manuscript }\end{array}$ \\
\hline
\end{tabular}

\section{References}

1. Kleffner I, Dorr J, Ringelstein M, et al. Diagnostic criteria for Susac syndrome. J Neurol Neurosurg Psychiatry 2016;87:1287-1295.

2. Vodopivec I, Prasad S. Treatment of Susac syndrome. Curr Treat Options Neurol 2016;18:3. 


\section{Neurology}

Mystery Case: Migraine, hearing loss, and blurred vision in a young woman

Sanskriti Sasikumar, Jonathan A. Micieli and Jiwon Oh

Neurology 2020;95;e2945-e2950 Published Online before print October 12, 2020

DOI 10.1212/WNL.0000000000011034

This information is current as of October 12, 2020

\section{Updated Information \&} Services

References

Subspecialty Collections

\section{Permissions \& Licensing}

Reprints including high resolution figures, can be found at: http://n.neurology.org/content/95/21/e2945.full

This article cites 12 articles, 2 of which you can access for free at: http://n.neurology.org/content/95/21/e2945.full\#ref-list-1

This article, along with others on similar topics, appears in the following collection(s):

\section{Audition}

http://n.neurology.org/cgi/collection/audition

Autoimmune diseases

http://n.neurology.org/cgi/collection/autoimmune_diseases

Migraine

http://n.neurology.org/cgi/collection/migraine

MRI

http://n.neurology.org/cgi/collection/mri

Visual loss

http://n.neurology.org/cgi/collection/visual_loss

Information about reproducing this article in parts (figures,tables) or in its entirety can be found online at:

http://www.neurology.org/about/about_the_journal\#permissions

Information about ordering reprints can be found online:

http://n.neurology.org/subscribers/advertise

Neurology ${ }^{\circledR}$ is the official journal of the American Academy of Neurology. Published continuously since 1951, it is now a weekly with 48 issues per year. Copyright () 2020 American Academy of Neurology. All rights reserved. Print ISSN: 0028-3878. Online ISSN: 1526-632X.

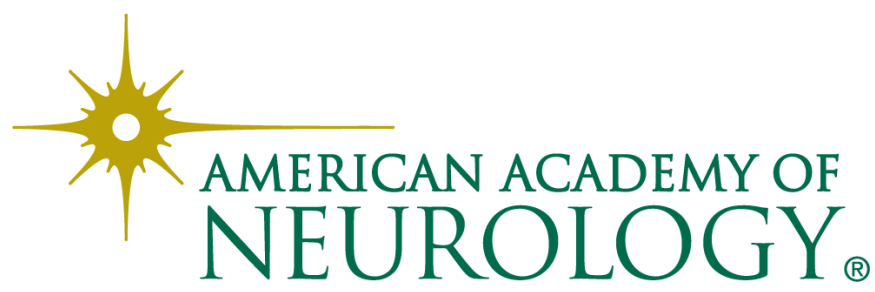

